\title{
Caring for transgender men
}

\author{
Trans Forming Practice: Life Stories of \\ Transgender Men that Change How \\ Health Providers Work \\ Marcus Greatheart MSW \\ Ethica Press; 2013
}

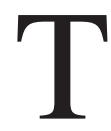
his slim book is the result of a road trip the author took along the west coast of the United States in 2007 where he interviewed a number of transgendered men and documented their stories of transition and of their posttransition lives. Despite the turbulence of their transition years, the stories demonstrated that these trans men could be "well adjusted and content with their lives." This is in contrast to the picture portrayed in psychiatric publications, which tend to see transgender issues in the context of "mental illness." The author recognized a gap between the medical/psychiatric approach to transgenderism and the reality that many trans men were not suffering from mental illness. His graduate research led to the writing of this book, which contains "recommendations for effective and culturally appropriate practice with trans communities."

This 170-page book is a welcome addition to the literature on transgender medical care. Each of the eight chapters tackles a different issue and together they support the author's thesis that much of the research on transgender issues has focused on the problems that these individuals experience and an alternative view that highlights transgender men's support systems, resources and competencies can help present "a more complex and nuanced exploration of gender transitions and transgender communities".

The core sections of this book highlight individual stories in the words of trans men. The most intriguing and

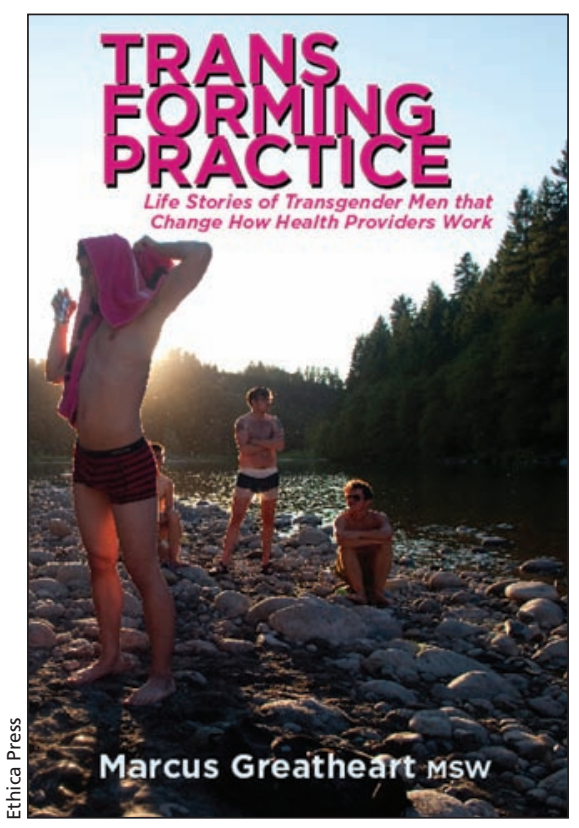

poignant story for me was an anecdote that contained a world of social and psychological significance. A natal female, "Ed" told how he had experienced the epiphany that he was transgender. He thought that he should be able to "pass" as a man in ordinary society. He had undergone top surgery, so he would no longer have breasts that (as an adult female) he would have to cover up in public. Now he was ready to try out his new top. But was the world ready for him? One hot summer's day he was relaxing in a rural area outside his hometown of Vancouver, British Columbia, when he decided that the time was right. He took off his shirt, revealing his newly breast-free male torso. He was pleased that, despite the fresh mastectomy scars, no one seemed to notice that he had, until recently, been a woman. In fact, a carload of young girls drove by and, recognizing him as a desirable male hunk, they whistled and waved and yelled at him. And he, ecstatic as any teenage boy would be with that affirmation of his masculine appearance, thought: "Yeah, who's the man!"

Another chapter is equally unique in presenting an assessment tool for transgender-related stress and trauma. The language of the tool, which is culturally specific and "trans-affirming," is designed to help clinicians acquire specific information from their trans clients. It can also help in a subtle way to create an atmosphere wherein the client feels more comfortable simply because the items in the tool make the clinician appear very savvy about transgender issues.

This first edition could benefit from editing changes. The contents section is right-justified - and therefore very difficult to read because of the varying lengths of the subtitles. Furthermore, the subtitles don't match the corresponding ones within the main text. In addition, the notation of references is not uniform. The book also lacks a methodology section, a major deficiency in a work that might otherwise be used as a template or starting point for additional studies on transgenderism, to see if the author's conclusions are generalizable to a larger population.

I presume that a second edition will correct these problems. If a substantial number of practitioners adopt the assessment tool, a new edition or a journal article will be needed, to present lessons learned and a second version of the tool.

I recommend Greatheart's Trans Forming Practice to everyone who is interested in transgender health care but clinicians in active practice will especially benefit from it.

Clayton L. Reynolds MD

Endocrinologist

Metchosin, BC

CMAJ 2014. DOI:10.1503/cmaj.130898 